\title{
Repair Effectiveness Studies on Impact Damaged Sandwich Composite Constructions
}

\author{
M. Raju, C. Rajasekhar Reddy, M. R. Narasimha Swamy and G. GiRidhaR \\ BMS College of Engineering, Bangalore
}

\author{
L. SRIKANTH, M. RAJENDRA PRAKASHI AND R. M. V. G. K. RAO* \\ Fibre Reinforced Plastics Division \\ National Aerospace Laboratories (NAL) \\ Bangalore-560017, India
}

\begin{abstract}
Experimental studies were carried out using sandwich conposite panel specimens, consisting of both polyurethane foam core (PUF) and aramid honeycomb.core (Nomex) type constructions. These specimens were subjected to inpact damage at energy levels ranging between 7.56 and 15.6J. A ply-drop-patching lechnique wals employed to repatir the impact damaged sandwich specimens. The undamaged (virgin), impact damaged, and repared specimens were then subjected to hexural (four point bending) and edgewise conpression tests and strength recoveries were measured to determine the efficacy of the repair technique employed. In hexure, strength recoveries of upto $97 \%$ in PUF core and $90 \%$ in honeycomb core sandwich specimens were realized after repair, whereas in compression, the corresponding values were upto $90 \%$ in PUF core and $\$ 8 \%$ in honeycomb core sandwich specimens. A repuir effectiveness factor $\left(R_{c i}\right)$ has been conceived and introduced to quantify the efficiency of the repair technique. Further, the repair quality was assessed using a simple NDT method prior to subjecting the sandwich specimens for destructive tests.
\end{abstract}

KEY WORDS: sandwich, impact damäge, composite repair, repair efficiency.

\section{INTRODUCTION}

7 IIE INCREASING USE of composites in both military and commercial aircraft requircs 1 the development of proven repair methods that restore the integrity of the damaged structure, with minimum degradation in its functional capability and weight addition. Further, the implementation of online repairs calls for simple procedures and gadgets to avoid excessive down time of the component. Therefore, continued and expanded use of composites critically depends on the development of both structurally adequate and ceonomically feasible, repair tcchniques.

Presently, one of the main concerns of the composite aircralt industry is multiple delamination damage caused by accidental impacts such as bird hits, runway debris, batte damage, etc. The extent of damage dictates the choice between repair of the component and its total replacement. Repairs involving adhesively bonded patches are preferred for composites, because bonding produces no holes (for fasteners), thus elminating regions of stress concentration. Ideally, the patch should be so designed and

Aviror to whom correspondence should be addressed.

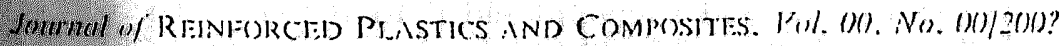


adhesively bonded to the parent laminate, so at to provide the most effective load transfer path across the repaired zone, and restore it as closely as possible to the status of the undamaged zone.

Thomson and Mouritz [1-3] carried out extensive studies on the degradation effects of impact damage on the mechanical properties of $\mathrm{PVC}$ foam core type sandwich beams through four-point bending and edgewise compression tests. Mines and Cheng [4] conducted compressive tests on low velocity impacted honeycomb core sundwich panels and the tests indicated that the residual strength decreased with increasing impact energy. Hart Smith's [5] tests on adhesive joints showed that stepped lap or scarf joint configurations give the strongest bonded joints and hence are employed for bonded patch repatirs. Milhdi et al. [6] halve presented the mechanical performance (four-point bending strength) of repaired honeycomb core composite sandwich beims, consisting of moulded prepreg skins and athesive films, employing overlap and searf repair schemes. Strength recovery of over 9()$^{\prime \prime \prime}$ wals recorded. Shah Khan and Grabovac [7] calrried oul studies on the elfect of replacement-core plug geometry with a step-lap skin repair scheme, on the strength recovery under fatigue loading of foam core sandwich specimens.

Usige of ready to use prepregs and adhesive lilns has been limited to certain specilic applications as they involve invariably more claborate and often, if not always, more expensive approaches. On the other hand, for the majority of routine applications, dannage zone repairs with wet-laminated composite patches (just in time prepregs) consisting of compatible fabric and resin systems are found to be useful in repairing of vacuum and resin injection moulded composite parts, thereby providing an inexpensive repair approach for applications such as the repair of battle damage [8].

This article is a result of efforts made to bring out a quantilied effectiveness of an inexpensive lield-friendly repair scheme based on a ply-drop-patching technique, for impact damaged sandwich panels, and its efficacy as applicable to both foam core and honeycomb core type RT-cured sandwich panel constructions.

\section{- EXPERIMENTAL DETALS}

\section{Materials Used}

The following matcrials were used in these studies:

1. E-Glass $2 \times 2$ twill bi-directional fabric of an areal density of $280 \mathrm{gsm}$ (supplied by $\mathrm{M} / \mathrm{s}$. Arun Fabrics, Bangalore, India).

2. Epoxy resin LY556+ hardener HY951 - RT cure system (supplied by M/s. Vantico Ltd., Mumbai, India).

3. PU foam core of $30 \mathrm{~mm}$ thickness and $85 \mathrm{~kg} / \mathrm{m}^{3}$ density (in-house developed).

4. Phenolic resin impregnated Aramid Nomex honeycomb core of $6.7 \mathrm{~mm}$ thickness (Hexcel HRH10) (supplied by M/s. Hexcel Corp.. USA).

\section{Test Specimen Preparation}

Sandwich pancls of $300 \times 300 \mathrm{~mm}^{2}$ consisted of three-ply GFRP skins on cither side of the core as shown schematically in Figure 1 . The skins were prepared by al wet lay-up process ensuring 0.65 liber-wcight fraction and vacuum-bonded to the core. The core

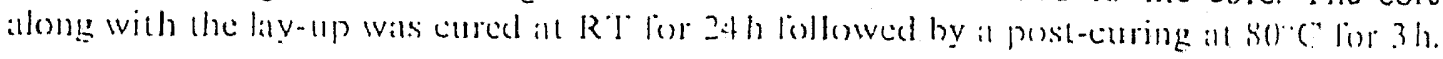


of curvalture of $12.7 \mathrm{~mm}$ and weighing $2.57 \mathrm{~kg}$, was dropped from heights ranging from 400 to $600 \mathrm{~mm}$ delivering 7.56 to $15.6 \mathrm{~J}$ of impact energy to the sindwich panel specimens.

Flexural and Elgewise Compression Tests

The sandwich specimens were tested in an INSTRON 6025 universal testing machine at a cross-head specd of $0.5 \mathrm{~mm} / \mathrm{min}$, equipped with a datia acquisition system, that wals used to record the lest dalta (toald, dellection, etc.).

A schematic view of the flexural and edgewise compression specimen (after impact damagc) under loading arc as shown in Figure 3(i) and (b).

The llexural strength $\left(\sigma_{1:}\right)$ and edgewise compression strength $\left(\sigma_{0}\right)$ of the silndwich specimens were carleulated as per the following lermulac:

$$
\begin{gathered}
\sigma_{1}=\frac{P L}{3((1)+c) / s} \\
\sigma_{\mathrm{C}}=\frac{P}{21 b}
\end{gathered}
$$

where the terms in the above equations refer to those depicted in Figure 3 (al) and (b).

(a)

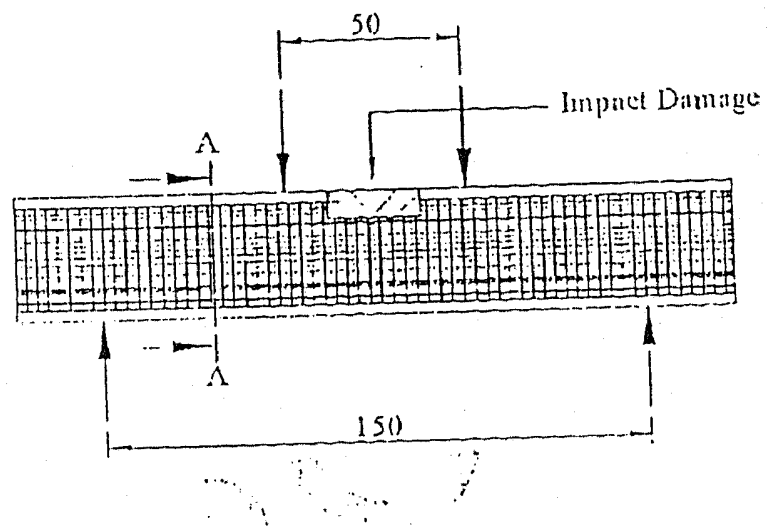

(b)

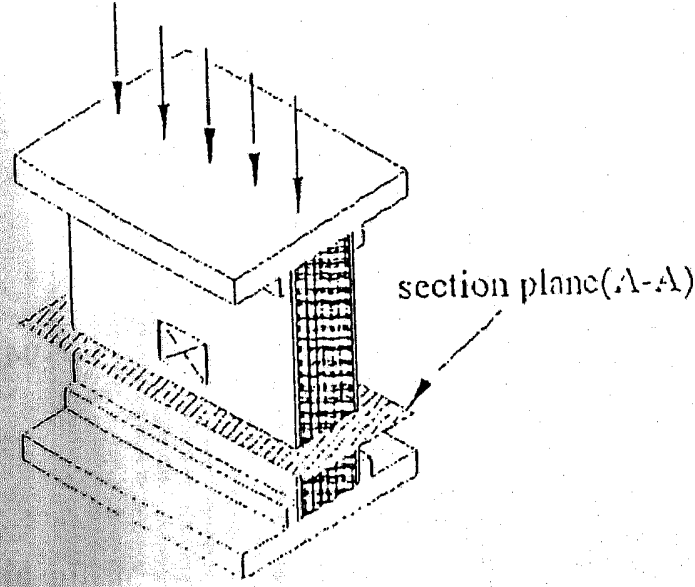

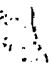
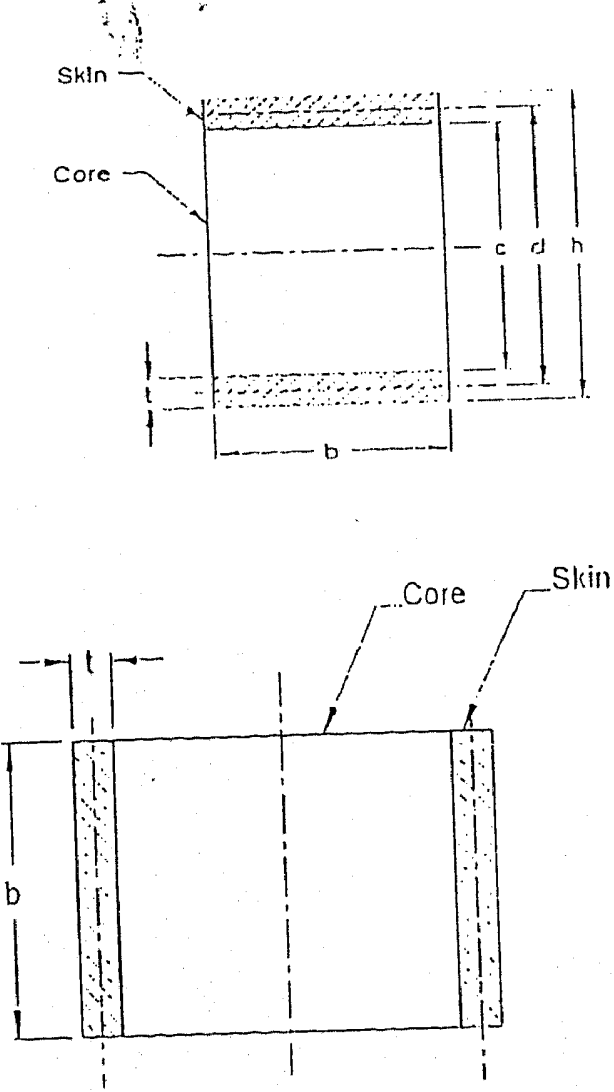

Figure 3. (a) A loaded llexural test specimen (damage on compression side) and (b) a loaded edgewise comprossion lest spocimen (damago on any side). 


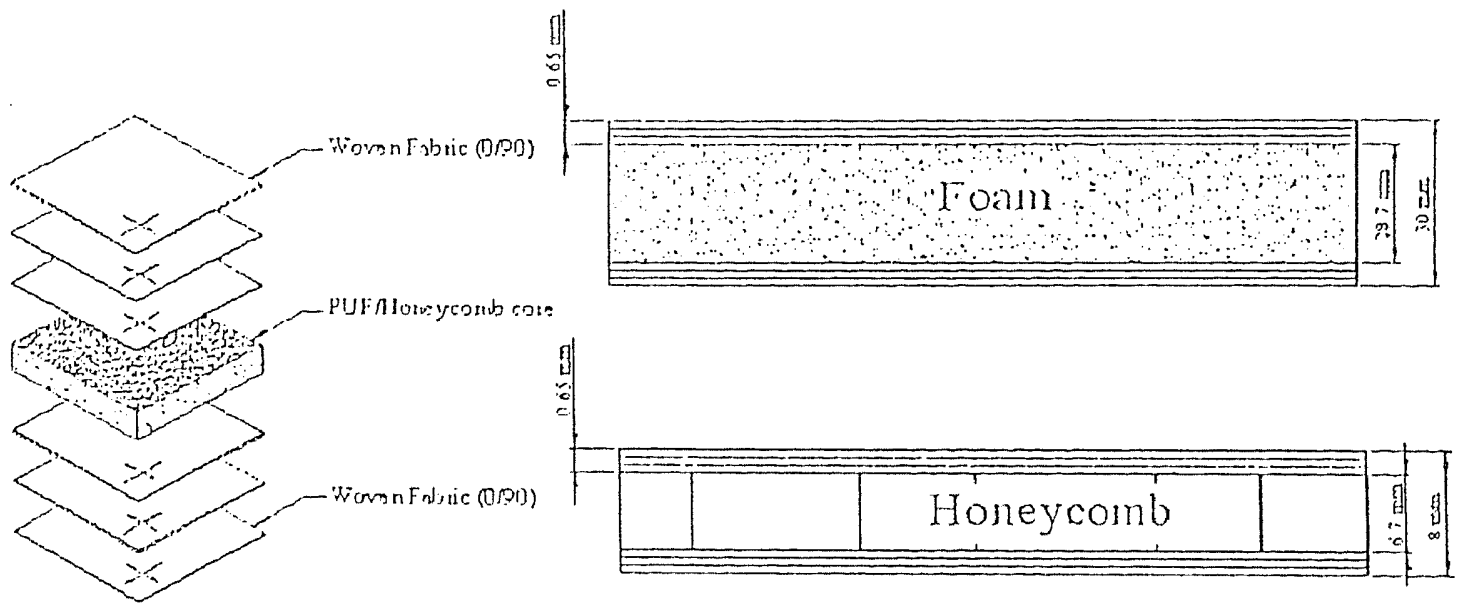

Figure 1. Schematic viow of sandwich constructions.
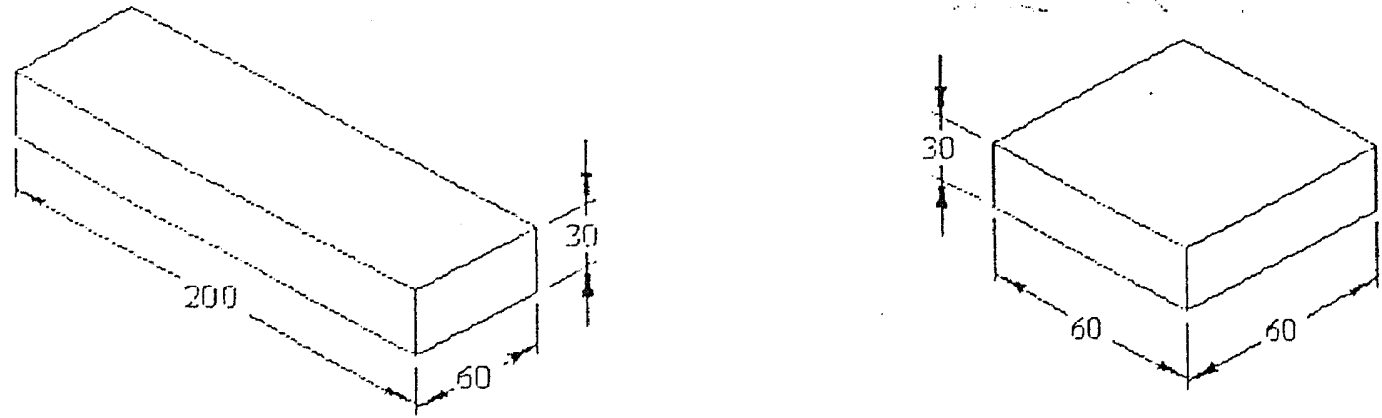

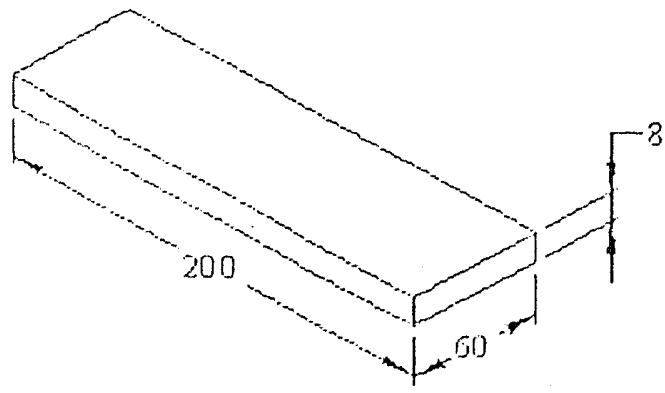

(a)

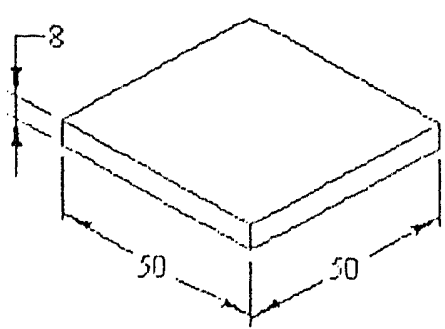

(b)

Figure 2. (a) Flexure test specimens and (b) edgewise compression test specimens.

The llexure (ASTM C 393) and edgewise compression specimens (ASTM C 364-94) prepared lor these studics are as shown in bigure 2 (a) and (b).

\section{Impact-damage of Test Specimens}

A scries of drop weight impacts were ciurried out on the sandwich pancls using an in-house developed apparalus [9], to conseptualize accidental impact damage calused due

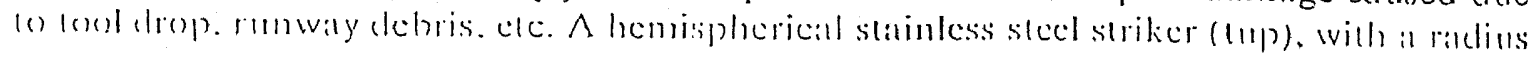


Reparir Silleme

An in-house developed ply-drop-patch repair scheme was used for carrying out repairs on impact damitged specimens. This involved the use of staggered wet pre-preg layers vacuum-bonded onto at suitably prepared damage-zone. To assess the repair quality of specimens prior to the mechanical tests, a priteticable Non-Destructive Test (NDT) was carricd out by lapping the virgin and repaired sandwich specimens, using the woodpecker device (WP632, Mitsui Japan make) working on the principle of acoustic emission, which is capable of detecting and digitally indiciting the presence of delaminations/debonds. The recovery of the woodpecker numbers in repaired specimens closer to those of virgin specimens is considered as an index of repar quality. Figures 47 present a pictorial view

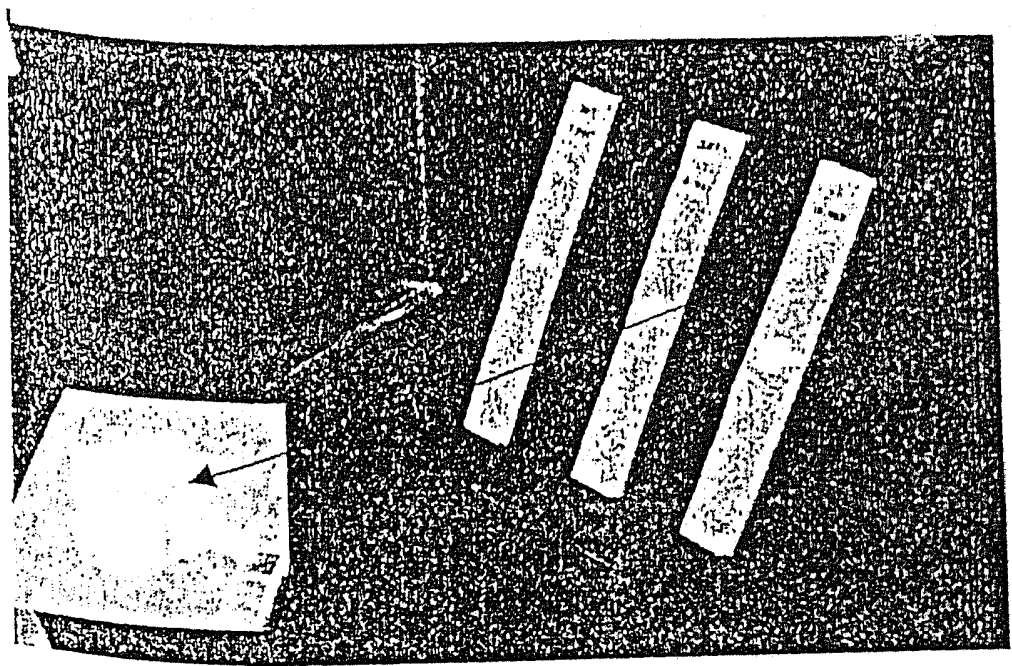

Figure 4. Impact damaged honeycomb sandwich flexural lest specimens.

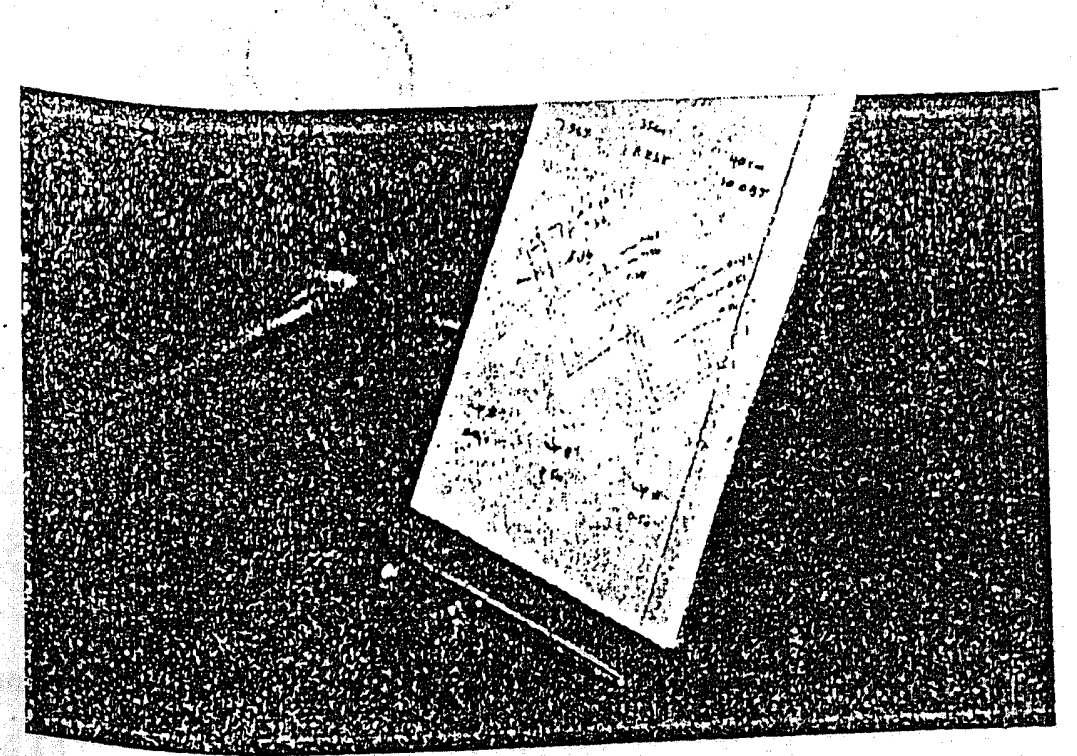

Figure 5. Repaired honeycomb sandwich flexural test specimens (woodpecker numbers marked). 

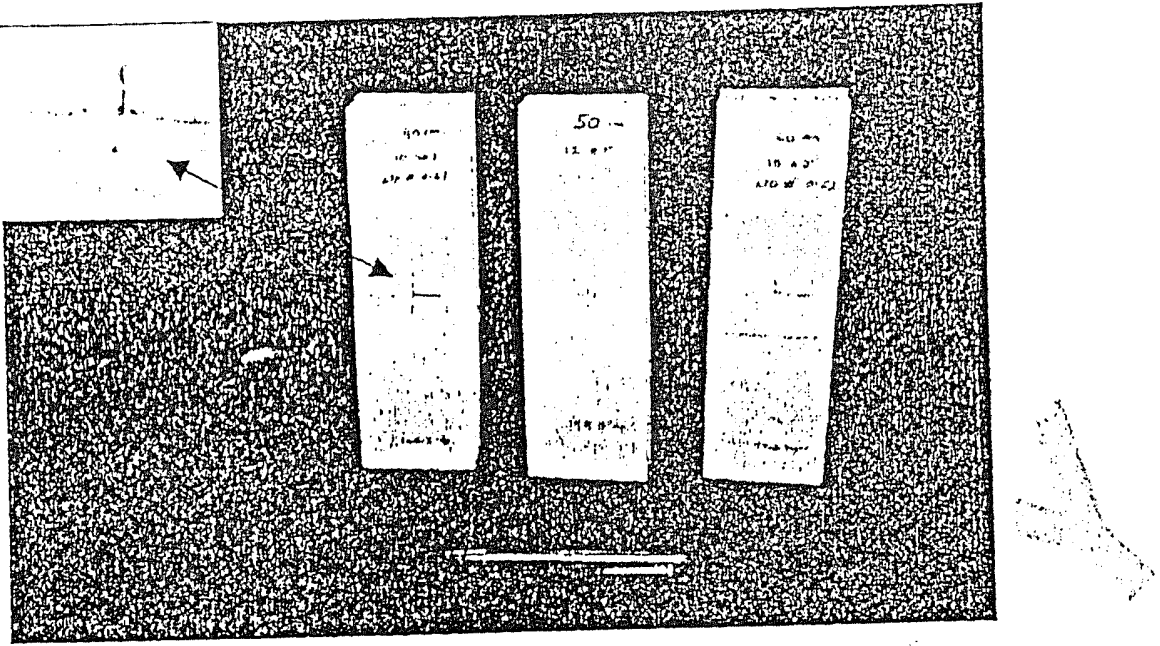

Figure 6. Impact damaged PUF core sandwich specimens subjected to flexural test.

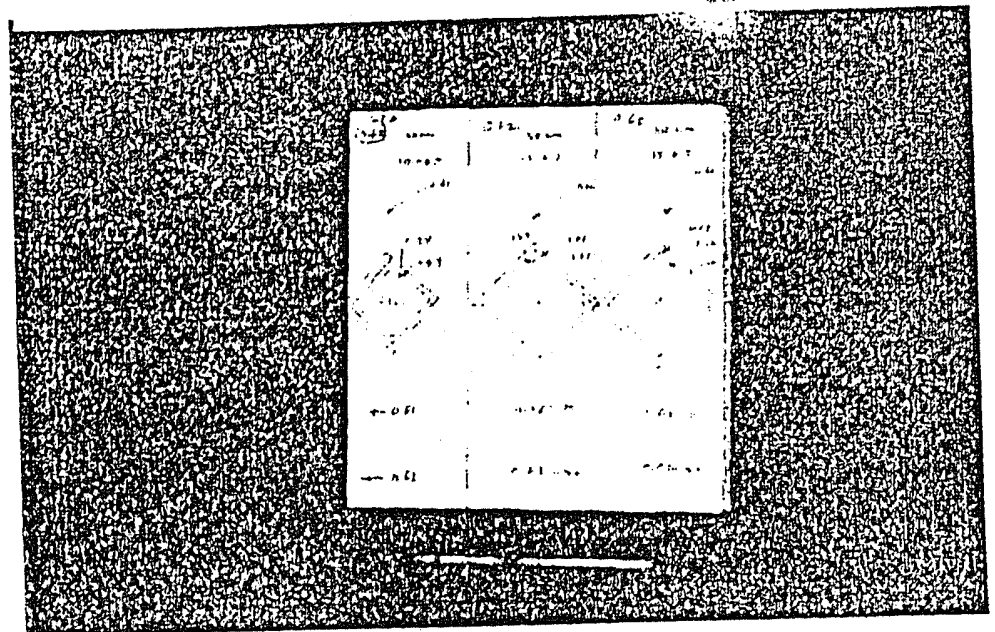

Figure 7. Repaired PUF core sandwich flexural test specimens (woodpecker numbers marked).

Table 1. NDT numbers indicating repair quality.

\begin{tabular}{lcc}
\hline & \multicolumn{2}{c}{ Woodpecker number } \\
\cline { 2 - 3 } Sandwich construction & Virgin specimen & Repaired specimen \\
\hline PUF & 0.61 & $0.58-0.62$ \\
Honeycomb & 0.54 & $0.54-0.60$ \\
\hline
\end{tabular}

of the damaged and repaired specimens of both types of sandivich constructions used in these studies.

The woodpecker mumbers (table 1), obtained both lor the virgin specimens (reference vallec), and the repaited ones. indicale al good repair guality. 


\section{RESULTS AND DISCUSSION}

The experimental results obtained, as average values of five test samples of sandwich constructions, at three different energy levels, are presented and discussed with respect to the following mechanical propertics:

- Flexural strength by four-point bending test, with the damalge present on the compression side of the test specimen.

- Edgewise compression strength, with damage present on one surface.

Based on the analysis of the above datal, at repair effectiveness factor $\left(R_{\mathrm{c}}\right)$, has been cvolved and presented for both types of sandwich specimens, in order to quantily and assess the repalir clficacy for this class of structural composites.

\section{Flexural Strength of Sandwich Specimens}

The virgin ( $\sigma_{F V}-$ reference value), residual $\left(\sigma_{F D}-\right.$ strength after damage), and recovered strength $\left(\sigma_{F R}-\right.$ strength after repair) of the sindwich specimens subjected to different impact energy levels are tabulated in Table 2.

Further, the percentage residual and recovered strength values, computed using the following expressions, are prescnted in Table 3.

$$
\begin{aligned}
& 1 / 10 \sigma_{1-1)}=\frac{\sigma_{F+12}}{\sigma_{F V}} \times 100 \\
& \% \sigma_{F-R}=\frac{\sigma_{F R}}{\sigma_{F V}} \times 100
\end{aligned}
$$

From Table 3 it can be seen that, percent residual llexural strength of the honcycomb core sandwich specimen decreases to about $50 \%$, but recoverable upto $90 \%$ of its virgin value. The corresponding values for the PUF core sandwich specimens are in the range $70-90 \%$ and $82-97 \%$, of the virgin values. The perent residual and recovered llexural strengths are as plotted in column diagrams (Figures 8 and 9 ).

\section{Edgewise Compression Strength of Sandwich Specimens}

The virgin ( $\sigma_{C V}$ - reference value), residual ( $\sigma_{C D}$ - strength after damage), and recovered compression strength ( $\sigma_{\mathrm{CR}}$ - strength after repair) ol sandwich specimens for different energy levels are tabulated in Table 4.

Table 2. Virgin, residual, and recovered flexural strengths (MPa) of PUF

\begin{tabular}{|c|c|c|c|c|c|c|}
\hline \multirow{2}{*}{$\begin{array}{l}\text { Impact } \\
\text { energy levels (J) }\end{array}$} & \multicolumn{3}{|c|}{ Honeycomb core sandwich specimens } & \multicolumn{3}{|c|}{ PUF core sandwich specimens } \\
\hline & $\pi_{F V}$ & $\sigma_{\mathrm{FD}}$ & $n_{\mathrm{FR}}$ & $o_{\mathrm{FV}}$ & $\sigma_{F D}$ & $\sigma_{\mathrm{FF}}$ \\
\hline Ref & 148.8 & - & - & 37.44 & - & - \\
\hline 7.56 & - & 71.8 & 133.9 & - & - & - \\
\hline 8.82 & - & 61.11 & 125.7 & - & - & - \\
\hline 10 & - & 53.46 & 121.9 & - & 34.27 & 36.42 \\
\hline 12.8 & - & - & - & - & 30.57 & 34.28 \\
\hline 15.6 & - & - & - & - & 25.98 & 31.05 \\
\hline
\end{tabular}
and honeycomb core sandwich specimens. 
Table 3. Percent residual and recovered flexural strengths of PUF and honeycomb core sandwich specimens.

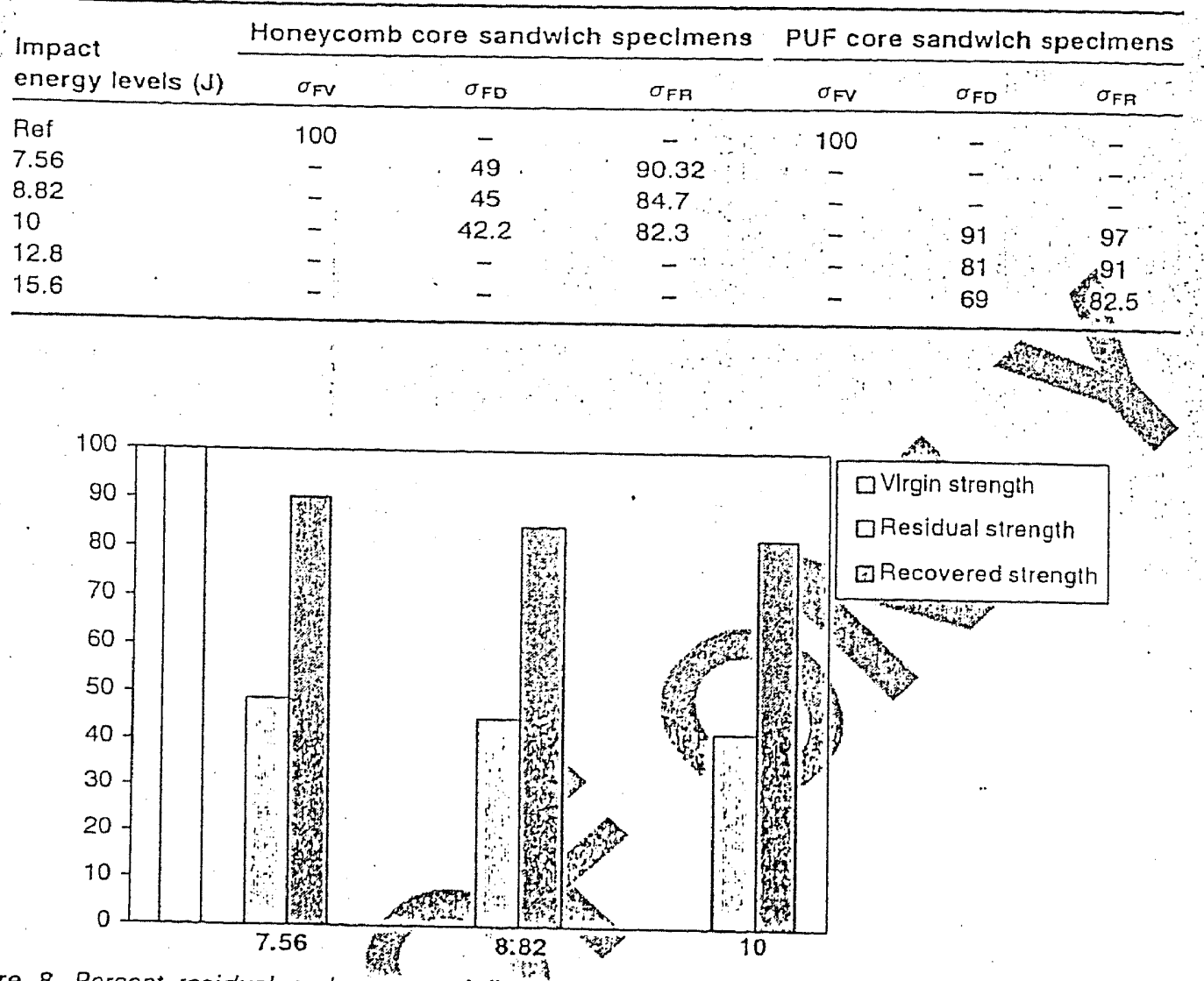

Figure 8. Percent residual and recovered flexural strengths of honeycomb core sandwich specimens. $X$-axis - impact energy; Y-axis.mperconitresidualfand recovered flexural strength.

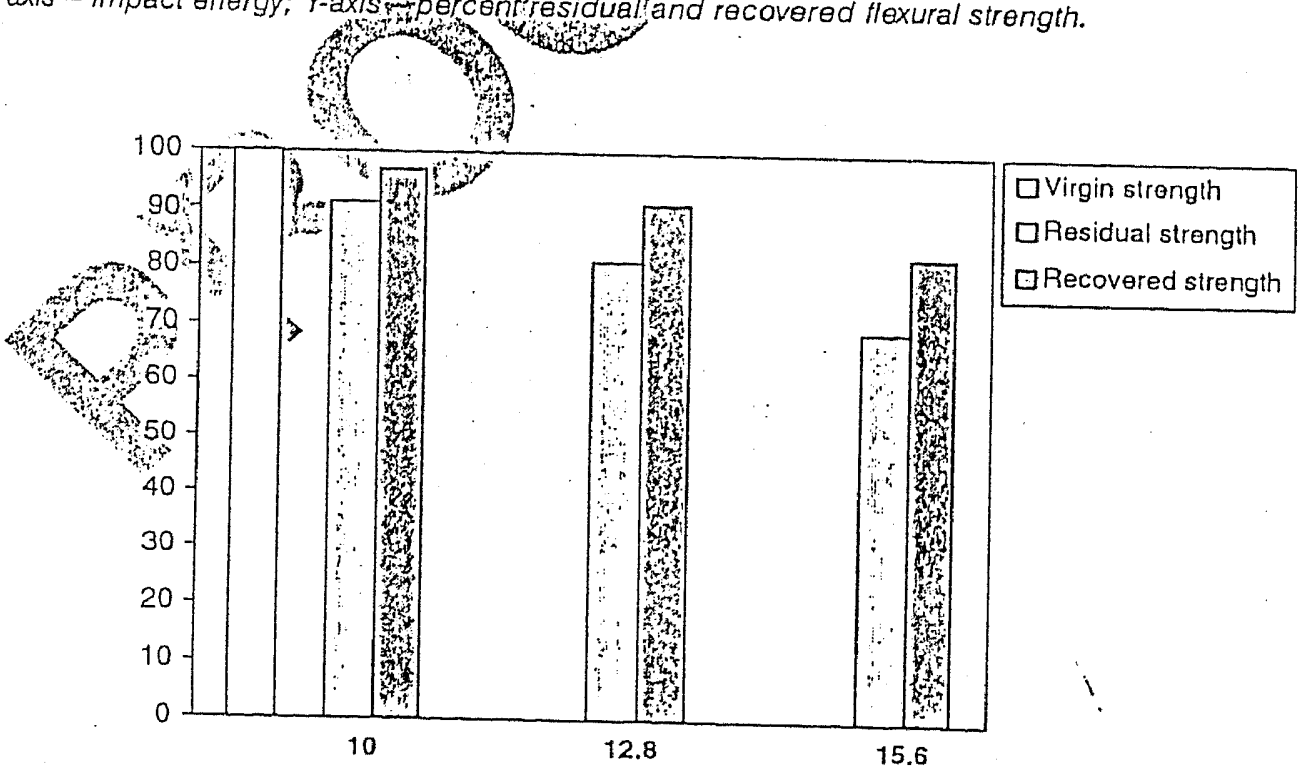

Figure 9. Percent residual and recovered flexural strengths of PUF core sandwich specimens. $X$-axis - impact energy; $Y$-axis - percent residual and recovered llexural strength. 
Studies on Impact Damaged Sandwich Composite Constructions

Table 4. Virgin, residual, and recovered compression strengths (MPa) of PUF and honeycomb core sandwich specimens.

\begin{tabular}{|c|c|c|c|c|c|c|}
\hline \multirow{2}{*}{$\begin{array}{l}\text { Impact } \\
\text { energy levels }(J)\end{array}$} & \multicolumn{3}{|c|}{ Honeycomb core sandwich specimens } & \multicolumn{3}{|c|}{ PUF core sandwich specimens } \\
\hline & $\sigma_{\mathrm{CV}}$ & $\sigma_{C D}$ & $\sigma_{C R}$ & $\sigma_{\mathrm{CV}}$ & $\sigma_{\mathrm{CD}}$ & $\sigma_{\mathrm{CR}}$ \\
\hline Ref & 275.17 & - & - & 138.76 & - & - \\
\hline 7.56 & - & 191.5 & 241.7 & - & - & - \\
\hline 8.82 & - & 167.3 & 224.8 & - & - & - \\
\hline 10 & - & 149.7 & 214.5 & - & 110 & 125.6 \\
\hline 12.8 & - & - & - & - & 90.67 & 108.87 \\
\hline 15.6 & - & - & - & - & 74.94 & 91.1 \\
\hline
\end{tabular}

Table 5. Percent residual and recovered compression strengths of PUF and honeycomb core sandwich specimens.

\begin{tabular}{|c|c|c|c|c|c|c|}
\hline \multirow{2}{*}{$\begin{array}{l}\text { Impact } \\
\text { energy levels (d) }\end{array}$} & \multicolumn{3}{|c|}{ Honeycomb core sandwich specimens } & \multicolumn{3}{|c|}{ PUF core sandwich specimens } \\
\hline & $\sigma_{\mathrm{CV}}$ & $\sigma_{\mathrm{CD}}$ & $\sigma_{\mathrm{CP}}$ & $\sigma_{\mathrm{cV}}$ & $\sigma_{\mathrm{CO}}$ & $\sigma_{\mathrm{CH}}$ \\
\hline Ref & 100 & - & - & $\cdots \cdot 100$ & - & - \\
\hline 7.56 & - & 69.63 & 87.83 & - & - & - \\
\hline 8.82 & - & 59 & 80.5 & $-i$ & - & - \\
\hline 10 & - & 54.4 & 78 & $-i$ & 79 & 90.5 \\
\hline 12.8 & - & - & - & - & 65 & 78.5 \\
\hline 15.6 & - & - & - & - & 54 & 66 \\
\hline
\end{tabular}

Further, these residual and recovered compression strength properties, computed as a percentage of the virgin strength $\left(\sigma_{C V}\right)$, using Expressions (3) and (4), are presented in Table 5 .

From Table 5 it can be scen that, percent residual compression strength of the honcycomb cole sandwich specinen decreases to about $50-70 \%$, but is recoverable upto $80-9()^{\prime \prime}$ of its virgin value. "The corresponding values for the PUF core sandwich specimens are in the same range. The perent residual and recovered compression strengths are as plotted in Figures 10 and 11 (column diagrams).

Repair Effectiveness Factor $\left(R_{\mathrm{e}}\right)$

To quantify the elficaly of the repair technique adopted, a repair elfectiveness lactor is introduced and delined as the ratio of the net strength recovered (difference of the recovered strength $-\sigma_{R}$ and residual strength $-\sigma_{D}$ ) to the net strength lost (difference of virgin strength $-\sigma_{V}$ and residual strength in a damaged specimen) and is as outlined bclow:

$$
R_{\mathrm{ei}}=\frac{\sigma_{R}-\sigma_{\mathrm{D}}}{\sigma_{\mathrm{V}}-\sigma_{\mathrm{D}}}
$$

The $R_{\text {ed }}$ indicates the elfectiveness of a repair technique on at scale of 0 and 1 . When

$$
\sigma_{R}=\sigma_{V}
$$




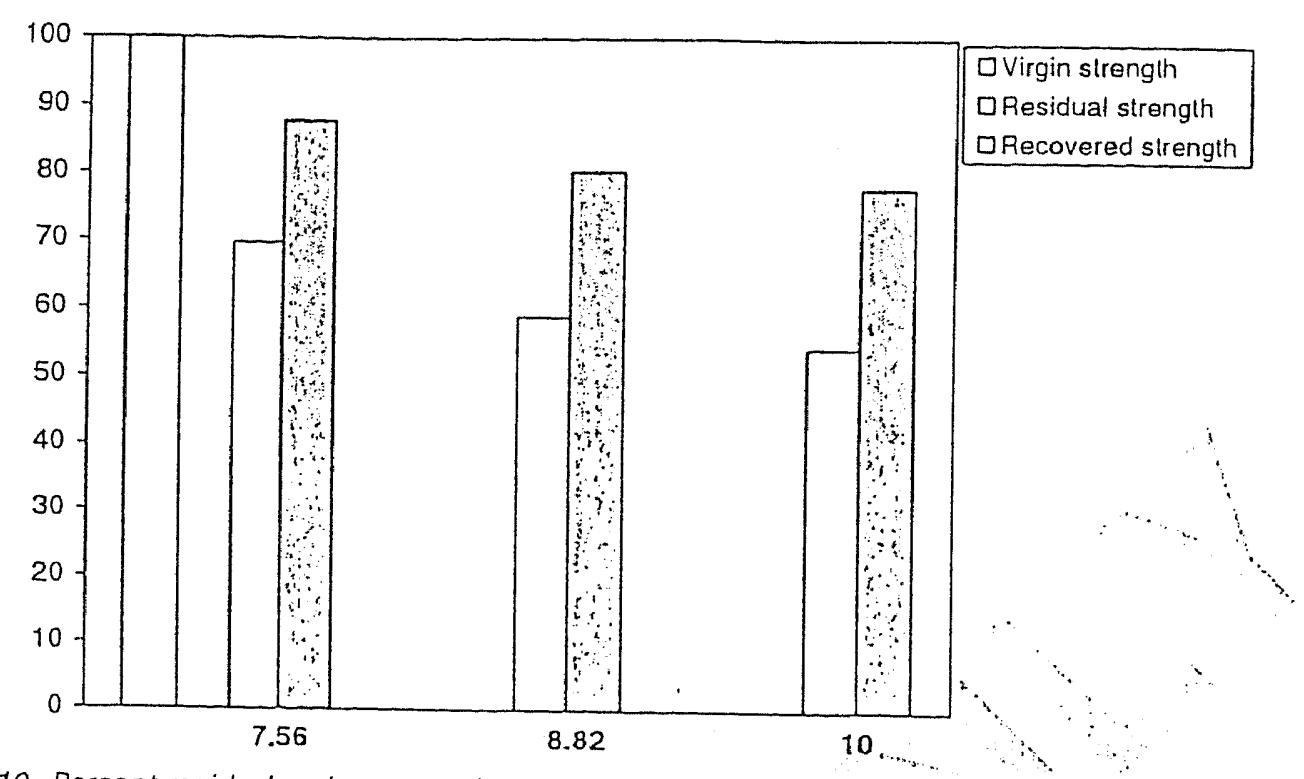

Figure 10. Percent residual and recovered compression strength of honeycomb core sandwich specimens. $X$-axis - impact energy; $Y$-axis - percent residual and recovered compression strength.

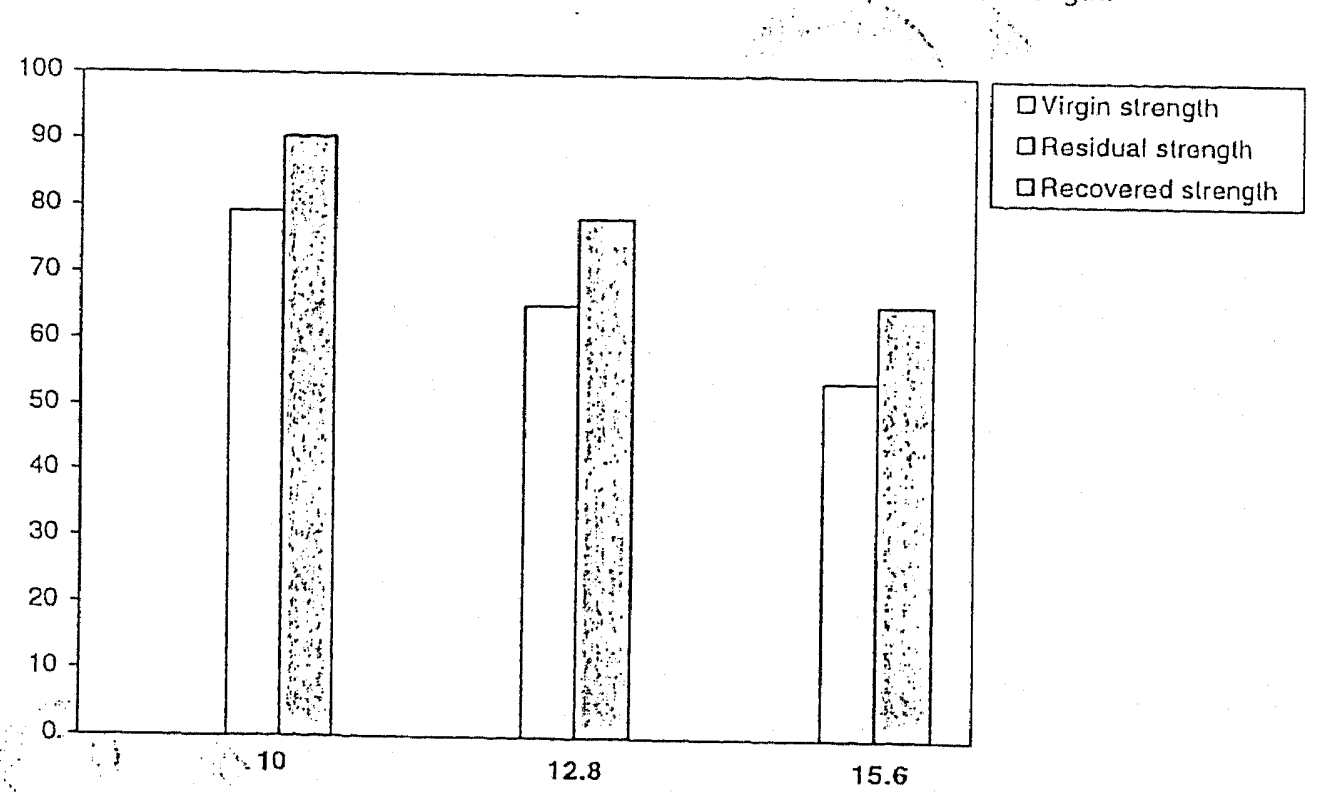

Figure 11. Percent residual and recovered compression strength of PUF core sandwich specimens. $X$-axis impact energy; Y-axis - percnt residual and recovered compression strength.

then, $R_{\mathrm{er}}=1$, indicating at total recovery of virgin strength due to repair. When

$$
\sigma_{\mathrm{R}}=\sigma_{\mathrm{D}}
$$

then, $R_{\mathrm{er}}=0$, indicating it zero recovery (an unsuccesslul repair).

Comparison of $R_{\mathrm{cr}}$ values for both types of sandwich constructions are tabulated in Table 6 and prescnted in Figure 12. 
Table 6. $R_{\mathrm{ef}}$ values for the repaired sandwich specimens.

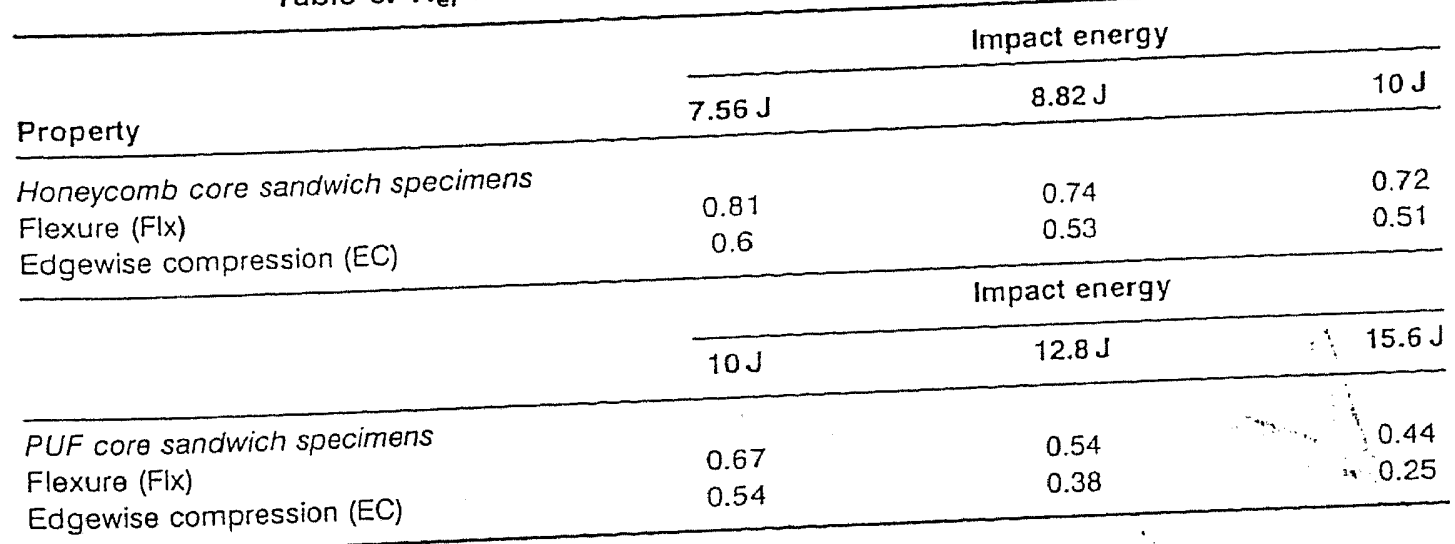

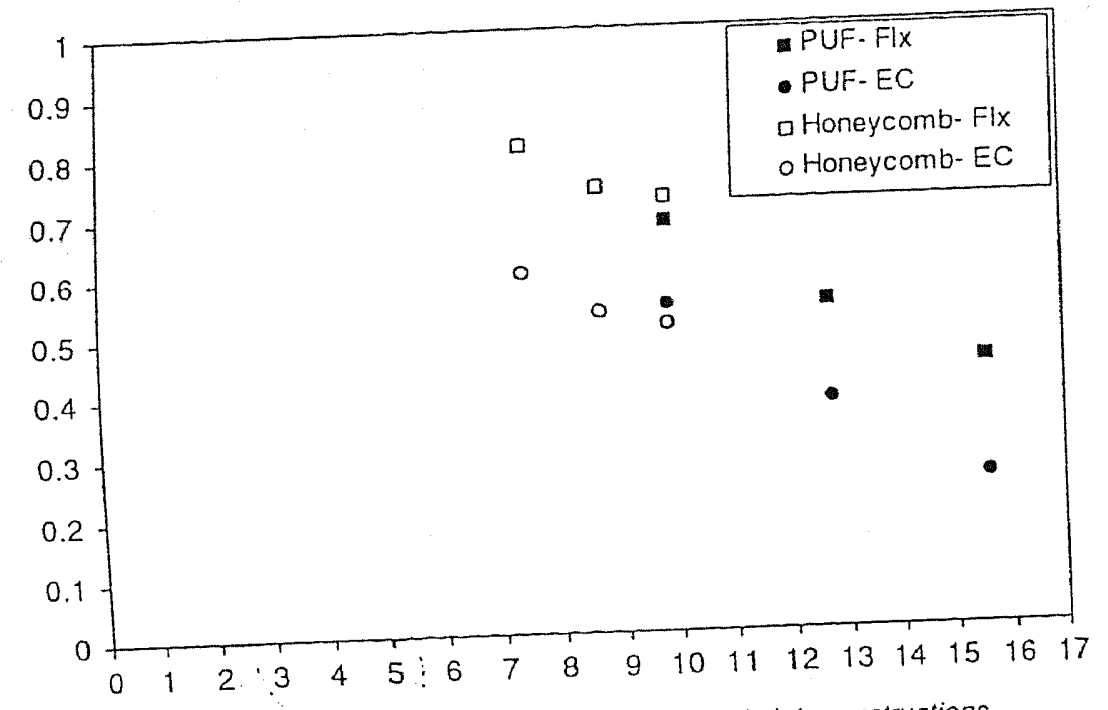

Figure 12. $R_{\text {ol }}$ values for both types of sandwich constructions.

\section{CONCLUSIONS}

- The percent recovered Mexural and edgewise compression strengths of the repaired specimens exhibited similar trends for both types of sandwich constructions.

- The overall recoveries in both types of sandwich specimens as quantilied by $R_{\mathrm{ct}}$ values, lic in the range of 0.5-0.81 for the honeycomb core sandwich specimens and $0.25-0.67$ in PUF core sandwich specimens. The $R_{\mathrm{er}}$ values decrease with increasing impact concrgy levels. However, for both types of sundwich constructions the repair elfectiveness in llexure is higher than that in edgewise compression loading.

- Both PUF and honcycomb core sandwich specimens showed companable repait

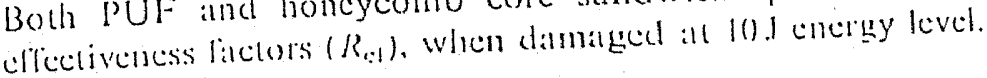




\section{ACKNOWLEDGMENT}

The atuthors arc thanklul to Dr B. R. Pai, Director. National Acrospace Laboratories, Bangalore, for all the support during the investigation.

\section{REFERENCES}

1. Thomson, R. S. and Mouritz (1999). Compression. Flexure and Shear Propertics of Sandwich Composites Containing Defects, Composite Structures, 44: 263-278.

2. Thomson. R. S. Shah Khan, M. Z. and Mouritz (1998). Shear Propertics of a Sandwichi Composites Containing Defects, Composite Structures, 42(2): 107-118.

3. Thomson, R. S. and Mouritz (1999). Skin Wrinkling in Impact Damaged Sandwich Composites, Journal of Sandsich Strucrures and Materials, 1(4): 299-322.

4. Mines and Cheng (1994). Response to Impact in Composites Containing Honeycomb, Journat of Beijing University.

5. Hant Smith, L. J. (1987). Design of Adhesively Bonded Joints, In: Joining of Fibre Reinforcerl Marerials, pp. 271-311, Elsevier, Applied Science.

6. Mahdi, S.. Kinloch. A. M. and Crisficld, M. ^. (2003). Static Mechanical Performance of Repaired Sandwich Panels - Part I, Journal of Sundwich Structures and Materials, 5(2): 179-202.

7. Shah Khan, M. Z. and Grabovac, I. (2000). Repair of Damage to Marine Sandwich Structures Part Il Fatiguc Loading, May 2000, DSTO-TN-275, DSTO Aeronautical and Maritime Research Laboratory, Melbourne, Australia (through internet).

8. Middleton, D. H. (1990)). Composite Aircraft Structures, Longman and Scientific Company.

9. Kumar, C. R., Radhakrishna, K. and Rato. R. M. V. G. K. (20014). Post Curing Erfects on Impract Behaviour of Composite Glass Epoxy Composite Laminates, Journat of Reinforced Plastics and Composites (in press).

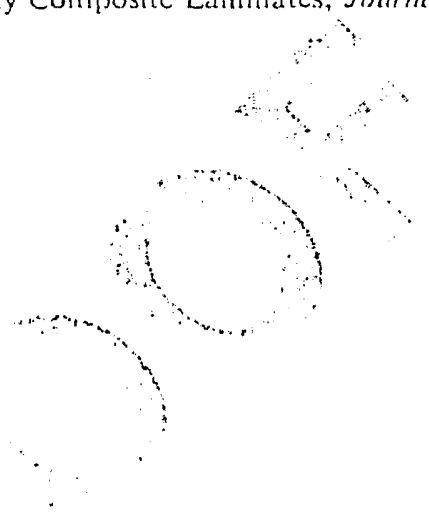

